Acta Crystallographica Section B

Structural

Science

ISSN 0108-7681

Sohrab Karami, ${ }^{a}$ Yang Li, ${ }^{a}$

David S. Hughes, ${ }^{a}$ Michael B. Hursthouse, ${ }^{\mathrm{a} *}$ Andrea E. Russell, ${ }^{\mathrm{a}}$ Terence L. Threlfall, ${ }^{a}$ Michael Claybourn $^{b}$ and Ronald Roberts ${ }^{b}$

${ }^{a}$ School of Chemistry, University of Southampton, Highfield, Southampton SO17 1BJ, England, and ${ }^{\mathbf{b}}$ AstraZeneca, Silk Road Business Park, Charter Way, Macclesfield, Cheshire SK10 2NA, England

Correspondence e-mail: mbh@soton.ac.uk

Received 10 February 2006

Accepted 2 May 2006

\section{Further errors in polymorph identification: furosemide and finasteride}

Reassessment of the reported single-crystal X-ray diffraction characterization of polymorphs of furosemide and finasteride shows that, in each case, incomplete data collections have resulted in the mistaken identification of two forms that are, in fact, identical.

\section{Introduction}

Over the years, a variety of techniques have been used for the purpose of characterization of solid forms in general and polymorphs in particular. These have included powder X-ray diffraction (PXRD), vibration spectroscopy, solid-state NMR spectroscopy, microscopy and differential scanning calorimetry. From time to time, full crystal structure determinations have been achieved in order to provide what are expected to be unequivocal characterizations of the solid forms. However, the assumption that single-crystal structure determination provides a clear benchmark in the identification of solid forms has to be viewed with some caution. A recent publication by Clemente \& Marzotto (2004) drew attention to the kinds of errors that can be made in the interpretation of single-crystal diffraction data, leading to false structural representations. The paper focuses on errors that occur through misinterpretations of space group symmetry, and amongst their examples are two examples of 'false polymorphism'. In a related development to this topic, van de Streek $\&$ Motherwell (2005) have recently described automatic procedures for searching the Cambridge Structural Database (CSD; Version 5.27 of November 2005; Allen, 2002) for, as yet, unrecognized polymorphs. These methods rely on comparisons of either or both computed PXRD patterns or reduced cell dimensions. The procedure can also identify 'false positives', i.e. pairs of structures that are falsely identified as polymorphs. In addition, the authors discuss the problems that can occur that might frustrate the automated process.

In the course of our own detailed study of polymorphic and related systems, we have discovered errors in the reporting of claimed polymorphism that have their origins in a form of misinterpretation that was not considered by Clemente \& Marzotto (2004). We report here on two such examples. A referee has kindly directed us to another report of similar occurrences to those discussed here (Hao et al., 2005).<smiles>CC(C)CNC(=O)C1CCC2C3CCC4NC(=O)C=CC4(C)C3CCC12C</smiles>

One of the compounds we have studied is the important diuretic furosemide (also called frusemide), (I), and we have identified a significant inconsistency in the published single-crystal work. We have also come across a similar occurrence in the case of finasteride, (II), a treatment for benign prostatic hyperplasia.
(C) 2006 International Union of Crystallography Printed in Great Britain - all rights reserved 
Details of our new interpretations are given below.

\section{Furosemide}

The first single-crystal structure determination was reported by Fronckowiak \& Hauptmann (1976; CSD refcode FURSEM). The structure was described as triclinic, with cell dimensions $a=5.251, b=$ 8.771, $c=15.038 \AA, \alpha=101.77, \beta=89.05, \gamma=97.57^{\circ}, V=672.09 \AA^{3}$, space group $P \overline{1}$, with $Z=2\left(Z^{\prime}=1\right)$. Lamotte et al. (1978; CSD refcode FURSEM01) reported a second structure determination of a pure form of the compound, also triclinic, with cell dimensions $a=10.467$, $b=15.801, c=9.584 \AA, \alpha=71.07, \beta=115.04, \gamma=108.48^{\circ}, V=$ $1332.84 \AA^{3}$, space group $P \overline{1}$, with $Z=4\left(Z^{\prime}=2\right)$. These authors commented on the fact that the two structures had the $b^{*} c^{*}$ planes in common, with the $a$ axis of the new structure twice that of the older one, but did not take the comparison further owing to lack of coordinate data for the first structure. The CSD also includes references to two reports of a further structure determination by Shin \& Jeon (1983; CSD refcodes FURSEM02 and FURSEM12), in which the structure was assigned a cell with $a=5.234, b=8.751, c=15.948 \AA$, $\alpha=$ $103.68, \beta=69.94, \gamma=95.59^{\circ}, V=666.58 \AA^{3}$, space group $P \overline{1}$, with $Z=2$ $\left(Z^{\prime}=1\right)$. Comparison of the 'reduced cells' (obtained by an automated procedure in which the flexibility in choosing a triclinic lattice is controlled by setting certain conventions) for this structure and that in the 1976 report indicates that the two are, in fact, the same. Use of the reduced cell comparison procedure does not provide an obvious link between the common structures of Shin \& Jeon (1983) and Lamotte et al. (1978).

In our work on polymorph screening for this compound, one crystallization from methanol produced small crystals growing around the side of the flask, whilst larger specimens grew on the floor of the flask. Using one of the small crystals, we found the smaller unit cell. Using a larger crystal, from the other region of the crystallization vessel, a unit cell analogous to that reported by Lamotte et al. (1978) was found but with different orientations of the unit-cell axes. Detailed analysis showed that the Lamotte et al. structure has two independent molecules in the asymmetric unit that differ only in the orientation of the two furan rings, whilst the small cell structure has disordered furan orientations. Fig. 1 shows the 'disordered' molecule of the first determination, together with the two molecules in the asymmetric unit of the correct determination.

The interpretation of this result is then quite simple. The arrangement of the molecules in the unit cell of the Lamotte et al. (1978) structure is such that the independent molecules lie alternately in analogous orientations along the $a$ axis; they differ in the furan
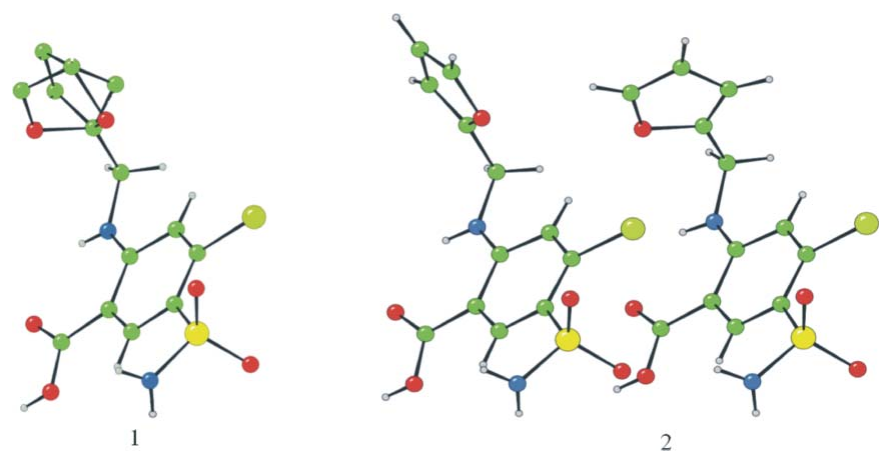

Figure 1

A diagram showing relative orientations of the asymmetric units of furosemide crystal structure 1 and furosemide structure 2 . orientations only. As a result the $h$ odd X-ray reflections receive contributions mainly from the atoms of the furan groups and are generally weak. In the cell determination of the small crystal, these were not picked up, so the halved cell was obtained, as in the published work. The choice of axes and angles for this cell corresponds to conventions for defining triclinic cells, which are encoded into most diffractometer software packages. The same convention, applied in the case of the doubled up, correct cell, obviously chose a cell that does not have obvious metric links to the cell for the halved structure. This is the reason for the failure to recognize the true relationship between the two results - they actually relate to only one form.

This interpretation is confirmed by computing the powder patterns using the published coordinates of Lamotte et al. (1978) and Shin \& Jeon (1983). In the data for the Shin \& Jeon structure, stored in the CSD, the coordinates of the minor fraction of the disorder are not included, as noted in the experimental comments. Note, however, that the $0.55 / 0.45$ disorder split should be $0.50 / 0.50$ if our interpretation is accepted. The patterns obtained are given in Fig. 2. The similarities are considerable but there are some differences. As can be seen, the missing fractional atoms affect a number of the intensities somewhat, which would give a low comparison figure in an automated scan. Subsequent inclusion of these atoms does improve the match considerably. This point is worthy of note for any use of CSD data where there is disorder.

\section{Finasteride}

Wawrzycka et al. (1999) reported data on four forms of finasteride. Two forms, 1 and 2 (CSD refcode WOLXOK), were described as pure compound polymorphs and two, forms $1 a$ (CSD refcode WOLXEA) and $1 b$ (CSD refcode WOLXIE), as pseudopolymorphs.

Form 1 has cell dimensions $a=6.451, b=12.741, c=25.979 \AA$, $\alpha=$ $\beta=\gamma=90^{\circ}, V=2135.2 \AA^{3}$, space group $P 22_{1} 2_{1} 2_{1}$, with $Z=4\left(Z^{\prime}=1\right)$. Full characterization was made by single-crystal structure determination, and the polymorph was confirmed to be a pure form. Form 2 was described as monoclinic, having cell dimensions $a=10.236, b=$ $7.948, c=13.896 \AA, \beta=95.84^{\circ}$. The space group was not reported, nor was the structure further determined. Wenslow et al. (2000) later reported the structure of a 'new' form of the pure compound (form II; CSD refcode WOLXOK03), with monoclinic cell dimensions $a=$ $16.387, b=7.958, c=18.115 \AA$ А $\beta=107.25^{\circ}, V=2256 \AA^{3}$, space group $P 2_{1}$, with $Z=8\left(Z^{\prime}=2\right)$. In this case, an immediate link is seen with the earlier structure, in that the $b$-axis dimensions are analogous. A detailed study shows that this unit cell corresponds to a doubling up

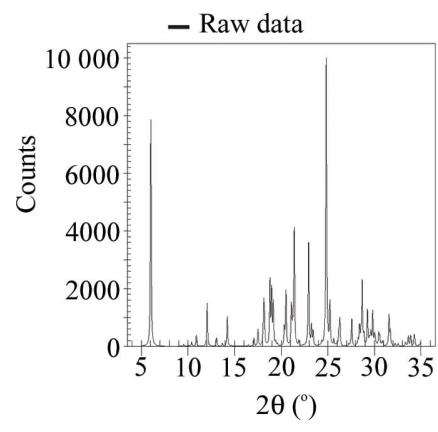

(a)

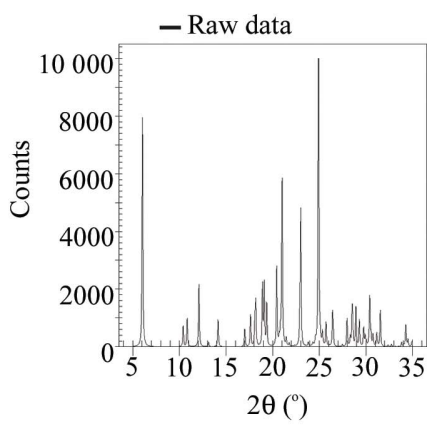

(b)
Figure 2

Calculated powder patterns for (a) the Lamotte et al. (1978) and (b) the Shin \& Jeon (1983) structures of furosemide. 
of the cell of the monoclinic form 2 of Wawrzycka et al. (1999), with a redefinition of axes. The transformation matrix from the Wawrzycka et al. form 2 cell to the Wenslow et al. cell is $(101 / 0 \overline{1} 0 / 10 \overline{1})$, leading to cell dimensions of $a=16.399, b=7.948, c=18.078 \AA$, $\beta=107.33^{\circ}$. These compare well with the cell for the Wenslow et al. form II. We are not able to provide a complete confirmation of this duplication, nor compare computed powder patterns, since the coordinates are not available for the earlier structure and we have not repeated the experimental work in this case. However, the Wenslow et al. form II structure shows strong pseudo- $B$ centring symmetry, which is an obvious source, again, of systematic weak reflections. We are very confident that the Wenslow et al. form II is the same as the claimed Wawrzycka et al. form 2 and is a genuine second polymorphic form.

\section{Conclusions}

These findings confirm quite clearly the value, in polymorphism studies in particular, of computing idealized PXRD patterns from single-crystal results. These are $(a)$ independent of cell orientation choice and $(b)$ easily compared with any experimental patterns. Whilst the automated approach to the detection of possible polymorphism is a very useful alerting process, any similarity coefficients that incorporate intensity values must be compared with soft constraints. Visual assessment of the patterns by an experimenter, who will likely have a quite flexible judgement, will also be advantageous. However, based on our experience in the furosemide study, when full crystal structural data are available, we find the Xpac procedure (Gelbrich \& Hursthouse, 2005) to give the clearest indication of any similarity or equivalence between structures.

\section{References}

Allen, F. H. (2002). Acta Cryst. B58, 380-388.

Clemente, D. A. \& Marzotto, A. (2004). Acta Cryst. B60, 287-292.

Fronckowiak, M. \& Hauptmann, H. (1976). Am. Abstr. Papers (Winter), p. 9.

Gelbrich, T. \& Hursthouse, M. B. (2005). CrystEngComm, 7, 324-336.

Hao, X., Parkin, S. \& Brock, C. P. (2005). Acta Cryst. B61, 675-688.

Lamotte, J., Campsteyn, H., Dupont, L. \& Vermeire, M. (1978). Acta Cryst. B34, 1657-1661.

Shin, W. \& Jeon, G. S. (1983). Proc. Collect. Natur. Sci. SNU, 8, 45-51.

Streek, J. van de \& Motherwell, S. (2005). Acta Cryst. B61, 504-510.

Wawrzycka, I., Stepniak, K., Matyjaszczyk, S., Koziol, A. E., Lis, T. \& Abboud, K. A. (1999). J. Mol. Struct. 474, 157-166.

Wenslow, R. M., Baum, M. W., Ball, R. G., McCauley, J. A. \& Varsolona, R. J. (2000). J. Pharm. Sci. 89, 1271-1277. 